\title{
Correction to: Intelligent Temperature and Vacuum Pressure Control System for a Thermionic Energy Converter
}

\author{
Bartosz Kania (D), Dariusz Kuś(D), Piotr Warda (D), \\ and Jarosław Sikora $(\mathbb{D}$
}

\section{Correction to:}

Chapter "Intelligent Temperature and Vacuum Pressure Control System for a Thermionic Energy Converter" in: A. Bartoszewicz et al. (Eds.): Advanced, Contemporary Control, AISC 1196, https://doi.org/10.1007/978-3-030-50936-1_22

In the original version of the book, the abstract of Chapter 22 was published with an incorrect information, "The results of the cathode temperature tests in the range from $1050 \mathrm{~K}$ to $1207 \mathrm{~K}$ show that at any time the pressure value in a TEC vacuum chamber is kept within the specified range," which has now been corrected to "The results of the cathode temperature tests in the range from $340 \mathrm{~K}$ to $1273 \mathrm{~K}$ show that any time the pressure value in a TEC vacuum chamber is kept within the specified range." The book and chapter have been updated with the changes. 